J. Dairy Sci. 92:581-588

doi:10.3168/jds.2008-1533

(C) American Dairy Science Association, 2009.

\title{
Weight distribution and gait in dairy cattle are affected by milking and late pregnancy
}

\author{
N. Chapinal, ${ }^{\star 1}$ A. M. de Passillé,† and J. Rushen† \\ *Animal Welfare Program, Faculty of Land and Food Systems, University of British Columbia, 2357 Main Mall, Vancouver, \\ British Columbia, V6T 1Z4, Canada \\ †Agriculture and Agri-Food Canada, PO Box 1000, Agassiz, British Columbia, V0M 1A0, Canada
}

\section{ABSTRACT}

There is increased interest in automated methods for lameness detection, such as measures of weight distribution. Still, practical use of such methods depends on knowing the conditions that affect how cows distribute their weight. In 3 experiments, 10, 18, and 12 Holstein cows were trained to stand on a platform that measured the weight placed on each of their legs. The objectives were to evaluate how cows change their weight distribution after milking, after calving, and when standing with the front legs elevated and to evaluate the effect of the udder fill and fetus weight on the gait score. Comparisons before and after milking and before and after calving showed that the weight of milk was carried mainly on the back legs, whereas the weight of the fetus was distributed between front (52\%) and back legs (48\%). The percentage of weight distributed between front and back legs was not affected by elevation of the front legs. Weight shifting between contralateral legs was greater before calving than after; the weight variability over time decreased by $30 \%$ after calving. A full udder increased gait score by $0.3 \pm 0.1$ and particularly abduction/adduction of the back legs (increased by $83 \%$ ). Gait score did not change after calving, although the back arch increased by $25 \%$. Therefore, time since milking and state of late pregnancy need consideration when using gait score and measures of weight distribution to detect lameness.

Key words: dairy cow, weight distribution, lameness, welfare

\section{INTRODUCTION}

Lameness is prevalent in modern dairy herds (Cook, 2003; Espejo et al., 2006) and has detrimental effects on economics and welfare. Unfortunately, dairy cattle

Received July 7, 2008.

Accepted October 23, 2008

${ }^{1}$ Corresponding author: chapinal@interchange.ubc.ca producers have difficulties detecting lame cows (Whay et al., 2003; Espejo et al., 2006), especially at the early stages of lameness. Traditionally lameness assessment relied on subjective methods of gait scoring, but large-scale assessments of gait scoring have found only moderate accuracy in detecting lame cows (Cramer, 2007). Behavioral changes associated with lameness in dairy cattle are often subtle (O'Callaghan et al., 2003), and gait may be affected by walking speed, which may reduce the accuracy of gait scoring in detecting hoof lesions. Furthermore, dairy herds are becoming larger and producers have less time to observe cows. Therefore, developing automated lameness detection tools for use on-farm may be helpful.

Rajkondawar et al. (2006) described how lame cows could be identified by an asymmetry in weight applied within a pair of legs, but this method has low accuracy in commercial conditions (Bicalho et al., 2007). Measuring the weight cows place on each of their legs when standing may be easier to implement on farms, and preliminary data showed that this method holds promise as a means of identifying lame cows (Pastell et al., 2006; Rushen et al., 2007; Kujala et al., 2008). Still, use of this technique in commercial conditions requires an understanding of how weight distribution is affected by factors other than lameness, such as udder fill in lactating cows and weight of the fetus in pregnant cows. For example, Flower et al. (2006) showed that certain gait attributes improved after milking and the presence of milk in the udder was likely affecting how cows distribute weight between their legs. Thus, the effectiveness of measures of weight distribution may be affected by the time since milking. Similarly, during pregnancy, the weight of the fetus may influence how cows distribute their weight between their legs.

Weight distribution may be affected by the way the cow is standing. For example, one common behavior seen in cows is to stand with the 2 front hooves in the stall. There is a positive correlation between time spent standing in this position and hoof lesions in the back hooves (Galindo and Broom, 2000). Possibly, when cows adopt this position there is a shift of weight from the 
front to the back that could be causing some stress due to extra weight placed on the back hooves influencing the high incidence of lesions in the back hoofs in the early stages of lactation (Leach et al., 1998; Livesey et al., 1998; Webster, 2001). Moreover, no studies have yet measured the change in weight distribution that results from this behavior. The objectives were to evaluate how cows changed their weight distribution after milking and after calving and when standing with the front legs elevated, and to evaluate the effect of the presence of a full udder and fetus on the gait score.

\section{MATERIALS AND METHODS}

In 2 experiments, how cows changed their weight distribution and gait score were measured before and after milking (experiment 1) and before and after calving (experiment 2). The effect of standing with the front legs elevated was looked at (similar to standing with the 2 front hooves in free stalls) on weight distribution (experiment 3).

\section{Animals and Housing}

Lactating Holstein cows were housed in sand bedded free-stalls $(2.4 \mathrm{~m}$ long $\times 1.2 \mathrm{~m}$ wide $\times 0.4 \mathrm{~m}$ deep $)$ at the University of British Columbia's Dairy Education and Research Centre in Agassiz, Canada. Cows were housed in groups of 12 to 36 cows, and there was at least 1 free-stall per cow. Cows were fed a TMR diet twice daily, formulated to meet requirements for dairy cows (NRC, 2001). Water was freely available from self-filling troughs. Lactating cows were milked in the parlor at approximately 0800 and $1700 \mathrm{~h}$ daily. The experimental protocol was approved by the Institutional Animal Care Committee, which is monitored by the Canadian Council on Animal Care.

\section{General Procedures and Measures}

Gait Score. Cows were scored by walking them down a $13 \mathrm{~m}$ long $\times 1.3 \mathrm{~m}$ wide nongrooved concrete passageway. A handler walked behind the cows, encouraging them to walk in a consistent manner. Cows were familiarized with the area and the procedure by repeatedly walking them down the passageway for at least $4 \mathrm{~d}$ ( 4 times/d) before they were scored. Each cow was videotaped at normal speed from her right side with a color digital camera (Sony DCRSR100 HDD Handycam Camcorder, Sony Corporation, Park Ridge, NJ, 30 frames $/ \mathrm{s}$ ) placed $8 \mathrm{~m}$ from the cow, which allowed recording at least 4 complete strides for each cow during each passage. A second video black-and-white camera (Panasonic CCTV WV-BP310; Matsushita
Electric, Mississauga, Ontario, Canada), connected to a time-lapse videocassette recorder (Panasonic TimeLapse VCR, AG-6740, at normal speed in 2-h mode, 25 frames/s), was mounted $2.7 \mathrm{~m}$ above the floor, pointed toward the rear of the cow, allowing scoring of abduction and adduction (swinging in/out) of the back legs. An experienced observer used these videos to score cow gait using a 1-to-5 numerical rating score system (NRS; where $1=$ perfect gait and $5=$ severely lame; Flower and Weary, 2006). Seven specific gait attributes (abduction/adduction of the back legs, back arch, head bob, tracking-up, joint flexion, asymmetric gait, and reluctance to bear weight) were evaluated using a 100unit continuous scale. A score of 0 represented a sound gait attribute, and 100 represented the most extreme example possible. The observer had proven a high degree of intraobserver reliability in a previous study (observer 2 in Flower and Weary, 2006).

Walking Speed. Two marks separated by $9.35 \mathrm{~m}$ were painted on the floor and walls of the same passageway. Using the same video recordings as for gait scoring, the time between when the nose of the cow was aligned with the starting and end mark was calculated using specialized software (The Observer, version 5, Noldus Information Technology, Wageningen, the Netherlands).

Weighing Platform. The distribution of weight among the legs was measured while cows were standing on a platform (Neveux et al., 2006), situated at the end of the passageway. Cows were familiarized with the platform and the procedure by standing on the platform 4 times/d for at least $4 \mathrm{~d}$ before they were recorded. The platform contained 4 independent recording units (each $56 \times 91 \mathrm{~cm})$ fitted in a $1.9 \times 1.3 \mathrm{~m}$ enclosure. The weight placed on each leg was recorded at a rate of 6 readings/s and to the nearest kilogram. The platform was calibrated daily during the experiments using deadweight calibration with standard weights. Individual leg and head positions of the cows were monitored using 3 black-and-white video cameras (front, back, and lateral view of the cow; Panasonic CCTV WVBP310) connected to a video multiplexer (Panasonic Video Multiplexer, WJ FS 416, at normal speed in 2-h mode, 25 frames/s), and a time-lapse video cassette recorder (Panasonic Time-Lapse VCR, AG-6740). These recordings were monitored to ensure that hooves and head were in the correct position throughout the period when weights were recorded. When hooves were not on the appropriate recording unit, or when the cow leaned the head on the restraining structure or turned the head back, the cow was gently manipulated to encourage repositioning. Readings in which the total weight recorded was $5 \%$ above or below the total weight mode within the passage were discarded. They always related 
to incorrect head or leg positioning when the cows were on the scale, as verified with the video recordings.

\section{Specific Experimental Procedures}

Experiment 1. The aim of this experiment was to assess how gait score and weight distribution change before and after milking. Ten lactating Holstein dairy cows (mean $\pm \mathrm{SD}$; parity $=3.9 \pm 1.6 ; \mathrm{BW}=662 \pm 46$ $\mathrm{kg} ; \mathrm{DIM}=66 \pm 43 \mathrm{~d}$; daily milk production $=45.2 \pm$ $6.7 \mathrm{~kg}$ ), previously trained to walk along the passageway and to stand on the weighing platform were used. They were divided into 5 pairs. Each pair was moved to a separate pen (of similar size and design to those described above) at least $2 \mathrm{~d}$ before data collection to acclimatize them to a different feeding schedule, where the cows had access to feed at least 60 min before milking. Three pairs were tested over 2 consecutive days, whereas 2 pairs were tested over $3 \mathrm{~d}$ to control for a change of milkers. Gait scoring and weight distribution measurements were taken daily no more than 60 min before and after routine morning milking. The first cow was taken from her pen before milking, walked along the passageway at least 4 times for gait scoring, and stood twice on the platform after the second and fourth walking passage, for 3 min each time. After all recording and measurements were completed, the cow was moved to the milking holding area for routine milking. The second cow was taken from the pen and the procedure repeated. After the first cow was milked, she was placed through the same procedures again. After milking, the second cow followed the same procedures a second time.

Experiment 2. The aim of this experiment was to assess how gait score and weight distribution change with calving. All cows and heifers in the farm expected to calve within $1 \mathrm{mo}$ were eligible for the experiment. Approximately 1 mo before the expected calving date, hoof health was assessed following the method described by Neveux et al. (2006). Cows found with severe hoof injuries such as dermatitis, sole ulcer, or interdigital fibroma were discarded. Three weeks before the expected calving date, animals were trained to walk along the passageway and stand on the weighing platform on 4 or 5 different days, for cows and heifers, respectively. On the last 2 training days, animals were recorded and gait scored as described before. Animals that would not stand still on the platform or whose NRS was greater than 3 were discarded because of interest in the effects of calving on healthy cows rather than on lame ones. Cows that were clinically lame were discarded from this trial because lameness may have acted as a confounding factor. Eventually, we selected 9 multiparous (parity =
$2.1 \pm 1.0 ; \mathrm{BW}=835 \pm 36 ; \mathrm{NRS}=2.7 \pm 0.4)$ and 9 nulliparous $(\mathrm{BW}=655 \pm 37$; NRS $=2.3 \pm 0.6)$ cows.

From 7 to $11 \mathrm{~d}$ before the expected calving date, cows were walked along the passageway at least 4 times for gait scoring and stood 3 times on the platform, for 3 min each time following the procedures described above. The same procedure was repeated within 24 to $72 \mathrm{~h}$ after calving, always after milking.

Experiment 3. The aim of this experiment was to assess how cows change their weight distribution when they stand with the front legs elevated. For this purpose, two 15-cm-high wooden boxes (same height as the curb in most free-stalls) covered with a rubber mat were attached to the front plates of the weighing platform.

Six primiparous lactating cows $(\mathrm{BW}=558 \pm 38 \mathrm{~kg}$; $\mathrm{DIM}=82 \pm 14 \mathrm{~d}$; daily milk production $=32.4 \pm 4.6$ $\mathrm{kg} ; \mathrm{NRS}=2.4 \pm 0.6)$ and 6 multiparous lactating cows (parity $=2.8 \pm 0.7 ; \mathrm{BW}=709 \pm 58 \mathrm{~kg} ; \mathrm{DIM}=73 \pm$ $18 \mathrm{~d}$; daily milk production $=54.2 \pm 6.9 \mathrm{~kg} ; \mathrm{NRS}=3.2$ \pm 0.3 ) that had been previously trained to walk along the passageway and to stand on the weighing platform were used. One week before starting the experiment, they were trained to stand on the weighing platform with the front plates elevated on 1 or 2 different days, for multiparous and primiparous cows, respectively.

Cows were tested on 2 consecutive days, and the 2 treatments (control or elevated front plates) were applied in an order that was balanced over cows. Each day, cows were walked along the passageway and stood on the weighing platform twice per treatment, $3 \mathrm{~min}$ each. The same procedure was performed the following day, inverting the sequence of the treatments.

\section{Statistical Analysis}

Of the 10 cows originally tested in experiment 1 , the weight distribution data from 2 of the cows could not be used because of technical difficulties with the platform. In experiment 1, PROC MIXED (SAS Institute, 2003), with a model that included cow as a random effect, treatment (before and after milking) as a repeated measure, and pair as a factor, and all the pair-wise interactions was used to test differences in NRS, gait attributes, speed, and weight applied to all 4 legs in response to treatment. The degrees of freedom were estimated by the Between-Within method. In addition, 2 more variables that have been suggested in the literature as indicators of lameness were used: a) the average SD of the load cell on each leg during the 3 -min period for a particular treatment as a measure of leg-load variability (Rushen et al., 2007), and b) the leg weight ratio (LWR) between the lighter and heavier leg of the front pair and of the back pair of 
Table 1. Least squares means $\left( \pm \mathrm{SED}^{1}\right)$ of the weight and variability over time of weight applied to the front and back legs before and after milking $(n=8$ cows $)$

\begin{tabular}{|c|c|c|c|c|}
\hline Item & Before milking & After milking & SED & $P$-value \\
\hline Weight front ${ }^{2}$ & $346(51 \%)$ & $343(53 \%)$ & 0.2 & $<0.001$ \\
\hline Weight back ${ }^{2}$ & $330(49 \%)$ & $304(47 \%)$ & 1.8 & $<0.001$ \\
\hline Front/back ${ }^{3}$ & 1.05 & 1.13 & 0.01 & $<0.001$ \\
\hline Front $\mathrm{LWR}^{4}$ & 0.90 & 0.88 & 0.03 & 0.55 \\
\hline Back LWR ${ }^{4}$ & 0.86 & 0.79 & 0.04 & 0.15 \\
\hline Front weight variability ${ }^{5}$ & 21 & 21 & 3.1 & 0.95 \\
\hline Back weight variability ${ }^{5}$ & 28 & 29 & 2.7 & 0.59 \\
\hline
\end{tabular}

${ }^{1}$ Standard error of the difference.

${ }^{2}$ Mean weight (kg) placed on each pair of legs (proportion of the total BW).

${ }^{3}$ Weight ratio between the sum of weight on the front legs and the back legs.

${ }^{4} \mathrm{Leg}$ weight ratio (LWR) is the ratio of weight placed on the lighter leg to the weight placed on the heavier leg of each pair of legs. This was done separately for the front pair of legs and the back pair of legs.

${ }^{5}$ Standard deviation of the weight placed on each limb over time expressed as the average of the 2 legs within a pair. SD was divided by BW for the analysis to account for the decreased BW after milking.

legs. These provided measures of asymmetry within the front and back pairs of legs (Pastell and Kujala, 2007). Differences in SD and LWR between treatments were tested with the same model described above. The SD was divided by BW for the analysis to account for differences between treatments within cow. Although none of the cows was obviously lame, the average NRS for each cow was included as a covariate when analyzing weight distribution and SD in case developing lameness affected weight distribution. The interaction between the NRS and all the other factors were included in the model. Because obviously lame cows were removed from the sample of cows, the NRS scores obtained did not cover the full range of possible gait scores. As a result the interactions between NRS and other factors were small and did not alter the pattern of results obtained. Consequently, they are not discussed further. To understand how aspects of gait interacted with each other, PROC CORR was used to correlate variables to one another (Pearson correlation).

Analyses for experiment 2 and 3 were similar to those described for experiment 1 . The model included cow as a random effect, treatment (before and after calving, or level and raised front legs) as a repeated measure, and parity as a factor. To test parity effect, weight applied to each pair of legs and SD were divided by BW for the analysis.

\section{RESULTS}

Following milking, there was a significant decrease in the weight applied to both the front and the back legs (Table 1). The weight placed on the back legs decreased after milking to a much larger extent than on the front legs (3 vs. $26 \mathrm{~kg}$ decrease). The weight distribution between the right and left side, the LWR, and the variability in the weight distribution over time for each limb or pair did not change after milking. The NRS decreased 0.3 points after milking, although walking speed remained the same (Table 2). The NRS was negatively correlated to walking speed before and after milking sessions $(\mathrm{r}=-0.87, P<0.001 ; \mathrm{r}=-0.71, P$ $=0.02$, respectively). Except for back arch and joint flexion and asymmetric gait, specific gait attributes decreased after milking, with the largest change occurring for rear leg abduction/adduction (Table 2). Walking speed was negatively correlated to tracking-up (before $=-0.80, P=0.02$; after $=-0.83, P=0.003)$, joint flexion (before $=-0.76, P=0.01$; after $=-0.89, P<$ 0.001 ), asymmetric gait (before $=-0.71, P=0.02$; after $=-0.85, P=0.002$ ), and reluctance to bear weight (before $=-0.72, P=0.02$; after $=-0.70, P=0.02$ ).

Following calving, there was an approximately $70-\mathrm{kg}$ decrease in the weight applied to both the front and the back legs (Table 3 ). The variability in weight distribution over time decreased after calving for all legs (more than $30 \%$ on average). The LWR did not change for the back legs. The NRS did not change after calving, but the degree of back arch increased (Table 4). Walking speed was not significantly correlated to NRS, but it was correlated to tracking-up $(\mathrm{r}=-0.57, P<0.001)$ and to flexibility $(\mathrm{r}=-0.37, P=0.03)$. Overall, primiparous cows had lower NRS than multiparous cows (2.5 vs. $3.1, \mathrm{SE}=0.2, P=0.03)$ and scored lower in asymmetric gait (31.0 vs. $35.4, \mathrm{SE}=2.1, P=0.03)$.

The results of experiment 3 show the weight distribution between pairs of legs and the variability of weight over time did not change by elevating the front legs (Table 5). Overall, primiparous cows placed a greater proportion of weight in the front and a lower proportion of weight in the back than multiparous cows (front/ back $=1.15$ vs. 1.08 for primiparous and multiparous cows, respectively, $\mathrm{SE}=0.01, P=0.008)$. 
Table 2. Least squares means $\left( \pm \mathrm{SED}^{1}\right)$ of gait-scoring variables before and after milking $(\mathrm{n}=10$ cows $)$

\begin{tabular}{lcccc}
\hline Item & Before milking & After milking & SED & $P$-value \\
\hline Speed (m/s) & 1.2 & 1.2 & 0.3 & 0.93 \\
NRS $^{2}$ & 3.1 & 2.8 & 0.1 & 0.01 \\
Abduction/adduction $^{3}$ & 29.8 & 16.3 & 2.5 & $<0.001$ \\
Back arch $^{3}$ & 28.3 & 26.8 & 1.8 & 0.46 \\
Head bob $^{3}$ & 5.5 & 2.3 & 1.2 & 0.03 \\
Tracking up $^{3}$ & 31.2 & 26.3 & 3.3 & 0.02 \\
Joint flexion $^{3}$ & 32.0 & 29.6 & 2.0 & 0.27 \\
Asymmetric gait $^{3}$ & 30.1 & 24.6 & 2.6 & 0.07 \\
Reluctance to bear weight $^{3}$ & 20.3 & 14.5 & 2.6 & 0.05 \\
${ }^{1}$ Standard error of the difference. & & & \\
${ }^{2}$ Numerical rating system (NRS) scored on a 5-point scale. & & & \\
${ }^{3}$ Variables were scored on continuous 100-unit visual analog scales. & & &
\end{tabular}

\section{DISCUSSION}

A full udder and a late stage of pregnancy affected some aspects of gait scores and measures of weight distribution. Most of the weight of the milk was carried on the back legs, whereas the weight of the late-stage fetus was evenly distributed among the legs. The results show the necessity of considering time since milking and stage of pregnancy when using gait scores or measures of weight distribution to detect lameness in dairy cows. Weight distribution did not change when cows stood with the 2 front legs elevated.

The results of experiment 1 showed that $89 \%$ of the weight of the milk was carried on the back legs. Neveux et al. (2006) found cows had difficulty shifting weight from the back legs to the front legs. Because the udder is situated close to the rear end of the cow, displacing some of this extra weight to the front legs may be difficult. The extra weight placed on the back legs due to udder fill may cause stress on the rear feet hooves during certain hours of the day. Most cases of lameness appear during peak lactation when the udder is heaviest (Leach et al., 1998; Livesey et al., 1998; Webster, 2001).

Measures of the variability of weight over time and the asymmetry of weight between contralateral legs estimated from the weighing platform readings were used to identify lame cows in small-scale studies (Pastell and Kujala, 2007; Rushen et al., 2007). The variability of weight over time is a measure of weight shifting between legs (Neveux et al., 2006; Pastell and Kujala, 2007; Rushen et al., 2007). Weight shifting and stepkick behavior while standing were indicators of pain or discomfort, which can be caused by hoof lesions in lame cows (Pastell and Kujala, 2007; Rushen et al., 2007). The variability of weight over time did not decrease after milking, suggesting that the full udder did not cause discomfort to cows while standing. The asym-

Table 3. Least squares means $\left( \pm \mathrm{SED}^{1}\right)$ of the weight and variability over time of weight applied to each pair of legs within 7 to $11 \mathrm{~d}$ before and 24 to $72 \mathrm{~h}$ after calving ( $\mathrm{n}=18$ cows)

\begin{tabular}{|c|c|c|c|c|}
\hline Item & Before calving & After calving & SED & $P$-value \\
\hline Weight front $^{2}$ & $390(52 \%)$ & $350(52 \%)$ & 3.6 & $<0.001$ \\
\hline Weight back ${ }^{2}$ & $353(48 \%)$ & $317(48 \%)$ & 4.7 & $<0.001$ \\
\hline Front/back ${ }^{3}$ & 1.10 & 1.10 & 0.01 & 0.95 \\
\hline Weight right $^{2}$ & $373(50 \%)$ & $335(50 \%)$ & 7.0 & $<0.001$ \\
\hline Weight left ${ }^{2}$ & $370(50 \%)$ & $331(50 \%)$ & 5.4 & $<0.001$ \\
\hline Right/left ${ }^{3}$ & 1.03 & 1.01 & 0.03 & 0.63 \\
\hline Front $\mathrm{LWR}^{4}$ & 0.88 & 0.91 & 0.01 & 0.04 \\
\hline Back LWR ${ }^{4}$ & 0.90 & 0.89 & 0.02 & 0.58 \\
\hline Front weight variability ${ }^{5}$ & 33 & 23 & 2.9 & 0.004 \\
\hline Back weight variability ${ }^{5}$ & 36 & 24 & 3.2 & 0.001 \\
\hline
\end{tabular}

${ }^{1}$ Standard error of the difference.

${ }^{2}$ Mean weight $(\mathrm{kg})$ placed on each pair of legs (percentage of the total BW).

${ }^{3}$ Weight ratio between the sum of weight on the front legs and the back legs.

${ }^{4} \mathrm{Leg}$ weight ratio (LWR) is the ratio of weight placed on the lighter leg to the weight placed on the heavier leg of each pair of legs. This was done separately for the front pair of legs and the back pair of legs.

${ }^{5}$ Standard deviation of the weight placed on each limb over time expressed as the average of the 2 legs within a pair. SD was divided by BW for the analysis to account for the decreased BW after calving and differences in BW related to parity. 
Table 4. Least squares means $\left( \pm \mathrm{SED}^{1}\right)$ of gait-scoring variables within 7 to $11 \mathrm{~d}$ before and 24 to $72 \mathrm{~h}$ after calving $(\mathrm{n}=18$ cows)

\begin{tabular}{|c|c|c|c|c|}
\hline Item & Before calving & After calving & SED & $P$-value \\
\hline Speed $(\mathrm{m} / \mathrm{s})$ & 1.4 & 1.3 & 0.04 & 0.06 \\
\hline $\mathrm{NRS}^{2}$ & 2.8 & 2.8 & 0.1 & 0.79 \\
\hline Abduction/adduction ${ }^{3}$ & 32.0 & 30.1 & 4.0 & 0.68 \\
\hline Back $\operatorname{arch}^{3}$ & 25.5 & 31.9 & 2.4 & 0.02 \\
\hline Head bob ${ }^{3,4}$ & 4.8 & 1.6 & - & - \\
\hline Tracking $u p^{3}$ & 10.1 & 15.8 & 3.2 & 0.11 \\
\hline Joint flexion $^{3}$ & 32.8 & 34.7 & 2.4 & 0.42 \\
\hline Asymmetric gait $^{3}$ & 35.4 & 31.0 & 1.9 & 0.04 \\
\hline Reluctance to bear weight ${ }^{3}$ & 15.9 & 14.3 & 2.8 & 0.58 \\
\hline
\end{tabular}

metry of weight between contralateral legs (LWR) did not change after milking. These findings suggest that measures of the variability over time in weight applied to the legs and the asymmetry of weight between contralateral legs, as potential indicators of lameness, may not be strongly influenced by time since last milking.

A full udder increased overall gait score and some specific gait attributes. Consequently, udder fill may interfere with lameness detection by gait scoring. Flower et al. (2006) found similar results, and those differences between cows with and without sole ulcers were greater after milking. Nevertheless, in their study, the effect of milking on gait score was confounded with the finding that cows were returning to their home pen from the milking parlor, which we were able to control. Gleeson et al. (2007) found that cows milked once daily during peak lactation presented distended udder due to the large volume of milk produced, and as a result, had some difficultly walking normally. In our study, the gait attribute that showed the greatest change after milking was abduction/adduction of the back legs, probably because of the changed volume of the udder. Boelling and Pollott (1998) suggested that the distended udders of mature cows formed an obstacle for the rear legs and forced them to describe a circle to circumvent the udder, impairing walking ability. Abduction/adduction is considered an important lameness indicator in some gait scoring systems (Manson and Leaver, 1988). Therefore, the use of this gait attribute as a measure of lameness may not be very reliable because udder fill may vary substantially across cows and phase of lactation and time of day within cow. Flower et al. (2007) noted that abduction/adduction did not differ between cows with and without sole ulcers and that intraobserver scoring consistency was low.

Although the effect of milking on gait was statistically significant, the small size of the effect raises questions about the biological significance. Rushen et al. (2007)

Table 5. Least squares means $\left( \pm \mathrm{SED}^{1}\right)$ of the weight and variability over time of weight applied to the front and back legs when cows stand on a level surface or with the front legs raised ( $\mathrm{n}=12$ cows)

\begin{tabular}{|c|c|c|c|c|}
\hline Item & Level front & Raised front & SED & $P$-value \\
\hline$\overline{\text { Weight front }}{ }^{2}$ & $333(52 \%)$ & $334(52 \%)$ & 0.8 & 0.08 \\
\hline Weight back ${ }^{2}$ & $303(48 \%)$ & $301(48 \%)$ & 1.3 & 0.38 \\
\hline Front/back ${ }^{3}$ & 1.11 & 1.12 & 0.01 & 0.16 \\
\hline Front $\mathrm{LWR}^{4}$ & 0.87 & 0.88 & 0.03 & 0.91 \\
\hline Back LWR ${ }^{4}$ & 0.90 & 0.85 & 0.02 & 0.09 \\
\hline Front weight variability ${ }^{5}$ & 18 & 17 & 1.3 & 0.60 \\
\hline Back weight variability ${ }^{5}$ & 20 & 22 & 2.1 & 0.14 \\
\hline
\end{tabular}

${ }^{1}$ Standard error of the difference.

${ }^{2}$ Mean weight (kg) placed on each pair of legs (percentage of the total BW).

${ }^{3}$ Weight ratio between the sum of weight of the 2 legs within a pair.

${ }^{4} \mathrm{Leg}$ weight ratio (LWR) is the ratio of weight placed on the lighter leg to the weight placed on the heavier leg of each pair of legs. This was done separately for the front pair of legs and the back pair of legs.

${ }^{5}$ Standard deviation of the weight placed on each limb over time expressed as the average of the 2 legs within a pair. SD was divided by BW for the analysis to account for differences in BW related to parity. 
found that local anesthetic had an effect on gait score that was of a similar magnitude, but had a much larger effect on measures of weight distribution. This suggests that the small magnitude of the effect may reflect the relatively low sensitivity of gait scoring compared with measures of weight distribution. Furthermore, in this study we excluded cows that were clinically lame. The effect of milking may be different for those cows.

Values for walking speed were of a similar magnitude to those reported in other studies (Flower et al., 2007). Flower et al. (2006) walked the cows on their way to the milking parlor and on their way back to the pen. Cows likely walk faster when returning to the pen, probably due to motivation to feed. Thus, the effect on walking speed may not be due to milking per se. We controlled for this effect and did not find any difference in speed before and after milking. Also, NRS and most of the gait attributes were negatively correlated to walking speed. A change in walking speed that is unrelated to lameness may then influence gait and affect the ability to detect lame cows through gait scoring.

The results of experiment 2 showed that the weight of the late-stage fetus was evenly distributed between the front and back legs (52 and 48\%, respectively) and the left and right sides (50\% each). In contrast to the udder, the fetus occupies a larger surface in the central rear part of the body. Therefore, there was no extra load on the back legs compared with the front ones. The weight change of about $70 \mathrm{~kg}$ before and after calving corresponded roughly to the weight of the calf, the placenta, and fluids, although some extra weight change could occur during the interval of 8 to $14 \mathrm{~d}$ between the weight measurements.

The variability of weight over time was greater before calving for both front and back legs. Cows may experience discomfort when standing in the late stages of their pregnancy, which makes them shift weight between legs. The front LWR increased after calving. Therefore, a late stage of pregnancy could be a confounding factor if weight shifting and asymmetry of weight between contralateral legs are to be used as indicators of lameness.

Gait score did not change overall after calving. Nonetheless, back arch increased after calving, perhaps because the cows were still recovering from parturition and felt some pain when walking. Gait asymmetry also decreased. The effect of calving on gait may be affected by the difficulty of the calving. Unfortunately, we did not follow a protocol to score the degree of dystocia and related trauma. Still, none of the cows suffered from an unusual degree of calving difficulty. Arching the back and slow walking were described as a sign of abdominal pain (Radostits et al., 1994). The back arch was considered an important lameness indicator in some gait scoring systems (Sprecher et al., 1997), although Flower et al. (2007) and Cramer (2007) reported difficulties using this gait attribute to detect cows with sole ulcers.

Standing with the 2 front hooves in the stall was related to lameness (Colam-Ainsworth et al., 1989). This behavior increases exposure of the back hooves to fecal material and hard floors, which were associated with increased prevalence of hoof diseases (Bergsten and Pettersson, 1992). Galindo and Broom (2000) found a relationship between the time cows spent standing with the 2 front hooves in the stall and heel erosion and dermatitis, but not claw lesions, and suggested that this behavior caused a reduction in heel depth of the back digits, predisposing them to infection in the interdigital tissue and heel. In experiment 3 , the weight distribution did not change when cows stood with the 2 front legs elevated. Therefore, cows did not shift weight from the front legs to the back legs as hypothesized. This suggests that cows may change leg angle to compensate for the elevation of the front legs to avoid shifting weight from the front to the back. Therefore, the relationship between time standing with the 2 front hooves in the stall and lameness seems mediated by the exposure of the back hooves to detrimental surfaces and not by an increase of weight load on the back hooves.

In agreement with previous findings (Greenough and Weaver, 1997; Neveux et al., 2006), cows placed more weight on the front legs (51 to $53 \%$ ) than on the back legs (47 to $49 \%$ ), which may result from anatomic differences in the front and back legs or from the weight of the head. The metacarpus is closer to the vertical than is the metatarsus, and flexion of the carpus allows a wider range of movement in the front than the back legs (Greenough and Weaver, 1997).

\section{CONCLUSIONS}

Comparisons before and after milking and before and after calving showed that most of the weight of the milk was carried on the back legs, whereas the weight of the late-stage fetus was evenly distributed among all legs. The percent of weight distributed between front and back legs was not affected by elevation of the front legs (in an attempt to imitate when cows stand with the 2 front hooves in the stall). Measures of weight distribution that have been proposed to detect lameness were affected most by late pregnancy and less by time relative to milking. In contrast, gait scores were most affected by time relative to milking. A full udder increased gait score, particularly abduction/adduction of the back legs. The degree of back arch increased after calving and there was less gait asymmetry. Therefore, time since milking and pregnancy need to be considered when using gait score and measures of weight distribution to detect lameness. Measures of weight 
distribution while cows are standing show potential as an automated method of detecting lameness, but the conditions that affect how cows distribute their weight must be understood before this method can be used in commercial conditions.

\section{ACKNOWLEDGMENTS}

We thank Gosia Zdanowicz, Kate Kjelsrud, Mairi Robertson, and the staff at The University of British Columbia's Dairy Education and Research Centre Agriculture and Agri-Food Canada for their help in running the experiments. The research was supported by the Natural Sciences and Engineering Research Council of Canada, the Animal Compassion Foundation, and Dairy Farmers of Canada.

\section{REFERENCES}

Bergsten, C., and B. Pettersson. 1992. The cleanliness of cows tied in stalls and the health of their hooves as influenced by the use of electric trainers. Prev. Vet. Med. 13:229-238.

Bicalho, R. C., S. H. Cheong, G. Cramer, and C. L. Guard. 2007. Association between a visual and an automated locomotion score in lactating Holstein cows. J. Dairy Sci. 90:3294-3300.

Boelling, D., and G. E. Pollott. 1998. Locomotion, lameness, hoof and leg traits in cattle. I. Phenotypic influences and relationships. Livest. Prod. Sci. 54:193-203.

Colam-Ainsworth, P., G. A. Lunn, R. C. Thomas, and R. G. Eddy. 1989. Behaviour of cows in cubicles and its possible relationship with laminitis in replacement dairy heifers. Vet. Rec. 125:573575 .

Cook, N. B. 2003. Prevalence of lameness among dairy cattle in Wisconsin as a function of housing type and stall surface. J. Am. Vet. Med. Assoc. 223:1324-1328.

Cramer, G. 2007. Quantification of foot lesions and an evaluation of early detection methods for lameness in Ontario dairy herds. PhD Thesis. Univ. Guelph, Guelph, Ontario, Canada.

Espejo, L. A., M. I. Endres, and J. A. Salfer. 2006. Prevalence of lameness in high-producing holstein cows housed in freestall barns in Minnesota. J. Dairy Sci. 89:3052-3058.

Flower, F. C., A. M. de Passillé, D. M. Weary, D. J. Sanderson, and J. Rushen. 2007. Softer, higher-friction flooring improves gait of cows with and without sole ulcers. J. Dairy Sci. 90:1235-1242.

Flower, F. C., D. J. Sanderson, and D. M. Weary. 2006. Effects of milking on dairy cow gait. J. Dairy Sci. 89:2084-2089.

Flower, F. C., and D. M. Weary. 2006. Effect of hoof pathologies on subjective assessments of dairy cow gait. J. Dairy Sci. 89:139146 .
Galindo, F., and D. M. Broom. 2000. The relationships between social behaviour of dairy cows and the occurrence of lameness in three herds. Res. Vet. Sci. 69:75-79.

Gleeson, D. E., B. O'Brien, L. Boyle, and B. Earley. 2007. Effect of milking frequency and nutritional level on aspects of the health and welfare of dairy cows. Animal 1:125-132.

Greenough, P. R., and A. D. Weaver. 1997. Lameness in Cattle. 3rd ed. W. B. Saunders, Philadelphia, PA.

SAS Institute. 2003. SAS User's Guide. SAS Institute Inc., Cary, NC.

Kujala, M., M. Pastell, and T. Soveri. 2008. Use of force sensors to detect and analyse lameness in dairy cows. Vet. Rec. 162:365368.

Leach, K. A., D. N. Logue, J. M. Randall, and S. A. Kempson. 1998 Claw lesions in dairy cattle: Methods for assessment of sole and white line lesions. Vet. J. 155:91-102.

Livesey, C. T., T. Harrington, A. M. Johnston, S. A. May, and J. A. Metcalf. 1998. The effect of diet and housing on the development of sole haemorrhages, white line haemorrhages and heel erosions in Holstein heifers. Anim. Sci. 67:9-16.

Manson, F. J., and J. D. Leaver. 1988. The influence of concentrate amount on locomotion and clinical lameness in dairy cattle. Anim. Prod. 47:185-190.

National Research Council. 2001. Nutrient Requirements of Dairy Cattle. Natl. Acad. Sci., Washington, DC.

Neveux, S., D. M. Weary, J. Rushen, M. A. von Keyserlingk, and A. M. de Passillé. 2006. Hoof discomfort changes how dairy cattle distribute their body weight. J. Dairy Sci. 89:2503-2509.

O'Callaghan, K. A., P. J. Cripps, D. Y. Downham, and R. D. Murray. 2003. Subjective and objective assessment of pain and discomfort due to lameness in dairy cattle. Anim. Welf. 12:605-610.

Pastell, M., H. Tamkko, H. Gröhn, M. Hautala, V. Poikalainen, J. Praks, I. Veermäe, M. Kujala, and J. Ahokas. 2006. Assessing cows' welfare: Weighing the cow in a milking robot. Biosystems Eng. 93:81-87.

Pastell, M. E., and M. Kujala. 2007. A probabilistic neural network model for lameness detection. J. Dairy Sci. 90:2283-2292.

Radostits, O. M., D. C. Blood, and C. C. Gay. 1994. Veterinary Medicine: A Textbook of the Diseases of Cattle, Sheep, Pigs, Goats, and Horses. 8th ed. Boillière Tindall, London, UK.

Rajkondawar, P. G., M. Liu, R. M. Dyer, N. K. Neerchal, U. Tasch, A. M. Lefcourt, B. Erez, and M. A. Varner. 2006. Comparison of models to identify lame cows based on gait and lesion scores, and limb movement variables. J. Dairy Sci. 89:4267-4275.

Rushen, J., E. Pombourcq, and A. M. d. Passillé. 2007. Validation of two measures of lameness in dairy cows. Appl. Anim. Behav. Sci. 106:173-177.

Sprecher, D. J., D. E. Hostetler, and J. B. Kaneene. 1997. A lameness scoring system that uses posture and gait to predict dairy cattle reproductive performance. Theriogenology 47:1179-1187.

Webster, A. J. 2001. Effects of housing and two forage diets on the development of claw horn lesions in dairy cows at first calving and in first lactation. Vet. J. 162:56-65.

Whay, H. R., D. C. Main, L. E. Green, and A. J. Webster. 2003. Assessment of the welfare of dairy cattle using animal-based measurements: Direct observations and investigation of farm records. Vet. Rec. 153:197-202. 